\title{
PHOTOMETRY OF COMET C/2009 P1 (GARRADD) BEFORE AND AFTER PERIHELION
}

\author{
S.F. Velichko ${ }^{1}$, M.V. Andreev ${ }^{2}$ \\ ${ }^{1}$ Institute of Astronomy of V.N. Karazin Kharkiv National University, Sumska 35, 61022 \\ Kharkiv, Ukraine, sergvelichko.sv@gmail.com \\ ${ }^{2}$ International Center for Astronomical, Medical and Ecological Research of the National \\ Academy of Sciences of Ukraine
}

ABSTRACT. During the period from September 2011 to February 2012, photometric observations of comet C/2009 P1 (Garradd) were performed on the 0.6-m telescope MC AMED at the peak Terskol (North-Caucasus).

The paper presents an analysis of photometric observations of Comet C/2009 P1 (Garradd) obtained for heliocentric distances of 2.0-2.1 au before and 1.7-1.8 au after perihelion passage. The measurements of the comet were performed using a $\mathrm{CCD}$ camera $\mathrm{SiTe} 003 \mathrm{AB}$ with narrowband comet filters $\mathrm{BC}(\lambda 4450 / 67 \AA), \operatorname{GC}(\lambda 5260 / 56 \AA)$, $\mathrm{RC}(\lambda 7128 / 58 \AA)$ and $\mathrm{C}_{2}(\lambda 5141 / 118 \AA), \mathrm{CN}(\lambda 3870 / 62 \AA)$ HB-set (Farnham T., 2000). Observation data were obtained during 11 nights.

According to the results of observations, the dust production Afo (A'Hearn M.F. et al., 1984) of comet, the gas production of comet for molecules $\mathrm{C}_{2}, \mathrm{CN}$ using the Hazer model (Haser L., 1957), dust-to-gas ratio and color were calculated.

The obtained results showed that the physical parameters of the comet are close to the average characteristics typical for dynamically new comets.

.Key words: comet, photometry, dust production, gas production, colour, dust-to-gas ratio.

АБСТРАКТ. В період з вересня 2011 року по лютий 2012 року були проведені фотометричні спостереження комети C/2009 P1 (Garradd) на 0,6-м телескопі Цейс-600 на піку Терскол (Північний Кавказ).

В статті представлені результати фотометричних досліджень комети C/2009 P1 (Garradd), отриманих на геліоцентричних відстанях 2,0-2,1 а.о. до перигелію та на відстанях 1,7-1,8 а.о. після. Спостереження комети виконані з використанням ПЗ3-камери $\mathrm{SiTe} 003 \mathrm{AB}$, яка була споряджена інтерференційними кометними фільтрами набору НB: $\mathrm{BC}(\lambda 4450 / 67 \AA), \quad \mathrm{GC} \quad(\lambda 5260 / 56 \AA)$, $\mathrm{RC}(\lambda 7128 / 58 \AA), \mathrm{C}_{2}(\lambda 5141 / 118 \AA)$ та $\mathrm{CN}(\lambda 3870 / 62 \AA)$. Дані спостереження були отримані протягом 11 ночей.

Отримані спостереження дозволили розрахувати

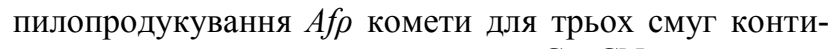
нууму, газопродукування молекул $\mathrm{C}_{2}, \mathrm{CN}$ комети, використовуючи модель Хазера, співвідношення пил-газ та колір пилу.
Отримані результати показали, що фізичні параметри комети близькі до середніх значень, характерних для динамічно нових комет та добре узгоджуються 3 результатами, отриманими іншими дослідниками.

Comet C/2009 P1 (Garradd) was discovered by Gordon J. Garradd (Siding Spring Observatory, Australia) in August 2009 at a heliocentric distance of $8.7 \mathrm{au}$. The comet passed through perihelion on December 23, $2011 \quad(r=1.55$ au) and was at closest approach to Earth on March 5, 2012 $(\Delta=1.27 \mathrm{au})$.

According to the orbit's parameters, such as eccentricity e, orbit inclination, semimajor axis, the comet refers to long-periodic ones which came to us from the Oort's cloud.

Observations of the comet by numerous researchers during 2011-2012 years showed high degree of CO abundance. Moreover, existence of main volatile components such as $\mathrm{H}_{2} \mathrm{O}, \mathrm{CO}, \mathrm{CH}_{4}, \mathrm{C} 2 \mathrm{H}_{2}, \mathrm{C}_{2} \mathrm{H}_{6}, \mathrm{HCN}, \mathrm{NH}_{3}, \mathrm{H}_{2} \mathrm{CO}, \mathrm{CH}_{3} \mathrm{OH}$ (Mumma et.al. 2012) was established. High abundance of $\mathrm{CO}$ was confirmed by space observations produced by the Deep Impact spacecraft (Feaga et.al. 2012), and the Hubble space telescope (Feldman et.al. 2012).

The comet C/2009 P1 Garradd was observed in the period from 17 of September to 19 of September 2011 before passing through perihelion as well as from 13 of February to 22 of February 2012 during ten nights.

The observations were carried out using the $60 \mathrm{~cm}$ telescope Zeiss-600 at the mountain observatory on PeakTerskol. As a radiation receiver the CCD camera Pixel-Vision Vienna was used. The camera was equipped by a narrowband filters HB-set in blue, green and red continuum spectrum ranges as well as $\mathrm{CN}$ and $\mathrm{C}_{2}$ emission lines. The receiver's field of view was 11 by 11 minutes with resolution of 0.63 seconds per pixel.

Reduction of images was carried out using standard method including bias and dark current subtracting, dividing by flat field as well as cleaning the images from cosmic particle tracks. As photometric standards the stars 96 Hercules and HD 120086 were used. Absolute fluxes in continuum ranges and emissions were derived using the method described in Farnharm's work(Farnham T., 2000). 


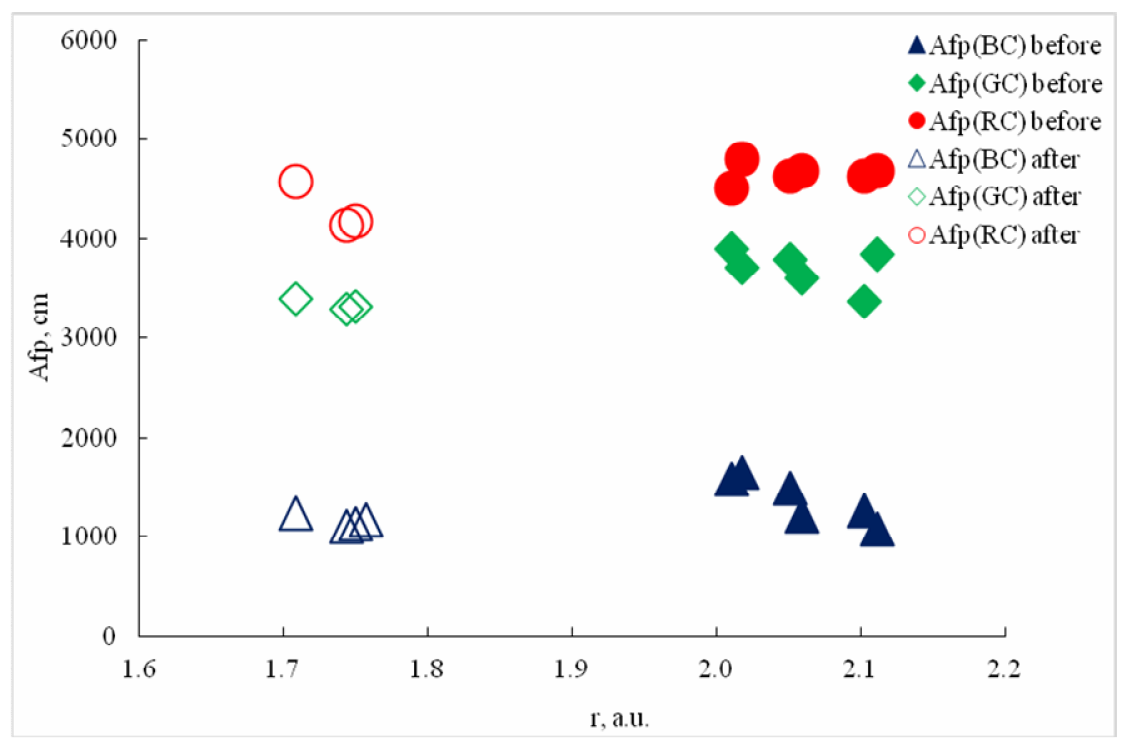

Figure 1: In the figure dependence of the Afp parameter on heliocentric distance is shown. Filled symbols are values before passing of perihelion while open symbols - after passing of perihelion in different continuum narrow band.

Table 1: Result of photometric measurements of comet C/2009 P1 (Garradd).

\begin{tabular}{cccccccccc}
\hline Date & UT, $\mathrm{h}$ & Airmass & r, a.u. & $\Delta$, a.u. & $\mathrm{CN}(3870 / 62 \AA)$ & $\mathrm{BC}(4450 / 67 \AA)$ & $\mathrm{C}_{2}(5141 / 118 \AA)$ & $\mathrm{GC}(5260 / 56 \AA)$ & $\mathrm{RC}(7128 / 58 \AA)$ \\
\hline $2011-09-07$ & 19.5 & 1.245 & 2.111 & 1.456 & $11.34 \pm 0.03$ & $11.74 \pm 0.02$ & $9.84 \pm 0.04$ & $10.34 \pm 0.03$ & $10.13 \pm 0.04$ \\
$2011-09-08$ & 19.8 & 1.330 & 2.102 & 1.464 & $10.50 \pm 0.02$ & $11.55 \pm 0.02$ & $10.53 \pm 0.04$ & $10.49 \pm 0.02$ & $10.14 \pm 0.03$ \\
$2011-09-13$ & 21.4 & 2.352 & 2.059 & 1.509 & $9.78 \pm 0.10$ & $11.59 \pm 0.12$ & $10.35 \pm 0.13$ & $10.40 \pm 0.06$ & $10.12 \pm 0.04$ \\
$2011-09-14$ & 21.2 & 2.276 & 2.051 & 1.518 & $9.63 \pm 0.12$ & $11.36 \pm 0.11$ & $10.44 \pm 0.08$ & $10.34 \pm 0.10$ & $10.13 \pm 0.11$ \\
$2011-09-18$ & 19.7 & 1.652 & 2.018 & 1.559 & $9.69 \pm 0.03$ & $11.24 \pm 0.03$ & $9.60 \pm 0.04$ & $10.36 \pm 0.02$ & $10.08 \pm 0.02$ \\
$2011-09-19$ & 19.9 & 1.774 & 2.010 & 1.570 & $9.75 \pm 0.05$ & $11.29 \pm 0.03$ & $9.74 \pm 0.02$ & $10.31 \pm 0.06$ \\
$2012-02-13$ & 23.9 & 1.429 & 1.708 & 1.387 & $----/ /----$ & $11.07 \pm 0.02$ & $9.84 \pm 0.03$ & $10.15 \pm 0.06$ \\
$2012-02-20$ & 2.5 & 1.053 & 1.744 & 1.329 & $10.03 \pm 0.07$ & $11.20 \pm 0.05$ & $10.40 \pm 0.03$ & $10.39 \pm 0.03$ & $9.75 \pm 0.06$ \\
$2012-02-21$ & 2.4 & 1.052 & 1.750 & 1.320 & $9.96 \pm 0.06$ & $11.17 \pm 0.04$ & $10.42 \pm 0.03$ & $10.39 \pm 0.03$ & $9.74 \pm 0.06$ \\
$2012-02-22$ & 2.2 & 1.059 & 1.757 & 1.313 & $10.14 \pm 0.07$ & $11.13 \pm 0.06$ & $----/ /----$ & $----/ /----$ \\
\hline
\end{tabular}

The results of the photometric measurements of comet are presented in the Table 1 . The Table 1 contains date of observations, air mass, helio - and geo-centric distances of the comet, its magnitudes for different filters with errors. For aperture photometry of the comet 20" - aperture was used.

Analysis of flux of solar radiation dispersed by the comet gives an opportunity to evaluate such characteristics of dust as dust production, colour, spectral gradient of reflectivity, gas-to-dust ratio.

To evaluate the rate of dust production in the comet from flux of its radiation in continuum the $A f p$ value is used. This value was introduced by A'Hearn et al. (A'Hearn M.F. et al., 1984) and is effective scattering cross-section of all particles falling into the field of view divided by projection of its field of view to the celestial sphere. The common equation present:

$$
A f \rho=\left(4 r^{2} * \Delta^{2} * 10^{0.4\left(m_{\text {sun }^{-}}{ }^{m}{ }_{\text {comet }}\right)}\right) / \rho \text {, }
$$

where the $A f \mathrm{p}$ itself is expressed in centimeters, $\Delta$ is geocentric distance expressed in centimeters as well, $r$ is heliocentric distance, in astronomical units, $\rho$ is the aperture radius used to integrate signal came from a comet and projected to the celestial sphere. The latter is expressed in centimeters.

In the Figure 1 dependence of the Afp parameter on heliocentric distance is shown. Filled symbols are values before passing of perihelion while open symbols - after passing of perihelion. As can be seen, dust production increases with approaching to the Sun and decreases with receding from the Sun. Also growth of dust production with wavelength length is seen. The latter indicates that redder particles prevail in the comet which corresponds to bigger sizes particles.

In the Table 2 results of calculations of dust production, gas-to-dust ratio and colours are presented. To characterize quantitatively the gas-to-dust ratio in comets ratio of flux measured in $\mathrm{C}_{2}$ band to flux measured in continuum $\mathrm{WC}_{2}=\mathrm{F}_{\mathrm{C} 2} / \mathrm{F}_{\mathrm{BC}}$ is commonly used. In case of comets with strong continuum equivalent width of the $\mathrm{C}_{2}$ band is in a range up to $500 \AA$.

Equivalent widths of the comet C/2009 P1 (Garradd) indicates that the comet refers to dust-reach ones. 
Table 2: Dust production, colours and gas-to-dust ratio of comet C/2009 P1 (Garradd).

\begin{tabular}{|c|c|c|c|c|c|c|c|c|c|c|c|}
\hline Date & UT, h & Airmass & r, a.u. & $\Delta$, a.u. & $\operatorname{Af} \rho(B C)$ & $\operatorname{Af} \rho(\mathrm{GC})$ & $\operatorname{Af} \rho(\mathrm{RC})$ & BC-GC & GC-RC & BC-RC & $\mathrm{W}\left(\mathrm{Fc}_{2} / \mathrm{Fbc}\right)$ \\
\hline 2011-09-07 & 19.5 & 1.245 & 2.111 & 1.456 & 1068.94 & 3849.64 & 4680.46 & 1.39 & 0.21 & 1.6 & 5.72 \\
\hline 2011-09-08 & 19.8 & 1.330 & 2.102 & 1.464 & 1266.43 & 3371.47 & 4622.53 & 1.06 & 0.34 & 1.41 & 2.55 \\
\hline 2011-09-13 & 21.4 & 2.352 & 2.059 & 1.509 & 1210.09 & 3608.29 & 4674.04 & 1.19 & 0.28 & 1.47 & 3.13 \\
\hline 2011-09-14 & 21.2 & 2.276 & 2.051 & 1.518 & 1488.75 & 3793.42 & 4631.38 & 1.02 & 0.22 & 1.23 & 2.33 \\
\hline 2011-09-18 & 19.7 & 1.652 & 2.018 & 1.559 & 1645.51 & 3707.8 & 4795.36 & 0.88 & 0.28 & 1.16 & 4.56 \\
\hline 2011-09-19 & 19.9 & 1.774 & 2.010 & 1.570 & 1576.07 & 3894.72 & 4501.23 & 0.98 & 0.16 & 1.14 & 4.18 \\
\hline $2012-02-13$ & 23.9 & 1.429 & 1.708 & 1.387 & 1228.03 & 3397.75 & 4577.99 & 0.73 & 0.7 & 1.43 & 3.1 \\
\hline $2012-02-20$ & 2.5 & 1.053 & 1.744 & 1.329 & 1095.67 & 3290.35 & 4140.68 & 0.8 & 0.64 & 1.44 & 2.09 \\
\hline 2012-02-21 & 2.4 & 1.052 & 1.750 & 1.320 & 1126.07 & 3307.97 & 4173.77 & 0.78 & 0.64 & 1.42 & 1.98 \\
\hline $2012-02-22$ & 2.2 & 1.059 & 1.757 & 1.313 & 1164.11 & -------- & ------- & -------- & -------- & ------- & ------- \\
\hline
\end{tabular}

Table 3: The gas production and column density of the comet C/2009 P1 (Garradd).

\begin{tabular}{ccccccc}
\hline \multirow{2}{*}{ Date } & r, a.u. & $\Delta$, a.u. & \multicolumn{2}{c}{$\mathrm{C}_{2}(5141 / 118 \AA)$} & \multicolumn{2}{c}{$\mathrm{CN}(3870 / 62 \AA)$} \\
& & & $\lg (\mathrm{N}), \mathrm{cm}-2$ & $\lg (\mathrm{Q}), \mathrm{mol} / \mathrm{s}$ & $\lg (\mathrm{N}), \mathrm{cm}-2$ & $\lg (\mathrm{Q}), \mathrm{mol} / \mathrm{s}$ \\
\hline $2011-09-07$ & 2.111 & 1.456 & 28.42 & 24.84 & 28.22 & 24.46 \\
$2011-09-08$ & 2.102 & 1.464 & 28.15 & 24.56 & 28.56 & 24.79 \\
$2011-09-13$ & 2.059 & 1.509 & 28.23 & 24.61 & 28.85 & 25.05 \\
$2011-09-14$ & 2.051 & 1.518 & 28.20 & 24.57 & 28.92 & 25.11 \\
$2011-09-18$ & 2.018 & 1.559 & 28.54 & 24.89 & 28.90 & 25.07 \\
$2011-09-19$ & 2.010 & 1.570 & 28.49 & 24.83 & 28.88 & 25.04 \\
& & & & & & \\
$2012-02-13$ & 1.708 & 1.387 & 28.20 & 24.56 & ---- & ---- \\
$2012-02-20$ & 1.744 & 1.329 & 27.96 & 24.56 & 28.50 & 24.72 \\
$2012-02-21$ & 1.750 & 1.320 & 27.94 & 24.35 & 28.53 & 24.76 \\
$2012-02-22$ & 1.757 & 1.313 & ----- & ---- & 28.45 & 24.69 \\
\hline
\end{tabular}

In the Table 3 values of gas production and column density of the comet derived using the Haser model (Haser L., 1957) are presented. The derived values of gas molecules production are typically for long-period comets and for dynamical new ones.

\section{Conclusions}

In this work the results of photometric observations of the comet C/2009 P1 (Garradd) before and after crossing of perihelion carried out from 17 of September 2011 to 22 of February 2012 during ten nights are presented.

Analysis of the photometric data has shown that the comet's continuum is redder than the solar one, colour excess in average is from 0.2 to 0.5 magnitude for different filters. As for steepness of spectral gradient of reflectivity, during the whole period of observations its value was equal 10 percent per $1000 \AA$ which is typical for majority of comets.

Evaluations of $A f p$, characterizing degree of dust production in the comet C/2009 P1 (Garradd), amounted from 1000 to 5500 centimeters in narrow-band filters cutting continuum. According to evaluations of colour and dust production, the comet C/2009 P1 (Garradd) refers to dustreach comets.

The values of gas molecules production derived are typical for long-period comets as well as for dynamical new ones.

Dynamical new, long-period comet C/2009 P1 (Garradd) refers to dust-reach comets.

\section{References}

Farnham T.: 2000, Icarus 147, 180-204.

Feaga L., et. al.: 2011, Proc. Conf. Baltimore, Maryland, USA, 30 July-3 August, 2011. ASP Conference Series. V. 457. P. 233.

Feldman P.D., et. al.: 2012, Proc. Conf. 2012. LPI Contribution № 1667. id. 6165.

Haser L.: 1957, Bull. Acad. Roy. Belgique, Classe des Sciences. V. 43. P. 740-750.

A'Hearn M.F. et al.: 1984, Astron. J. V. 89. P. 579-591.

Mumma M.J., et al.: 2012, Amer. Astron. Soc. DPS Meeing 44, 506.07. 